\title{
Temperature Dependence of the Urbach Energy in Lead Iodide Perovskites
}

Martin Ledinsky(1)*; Tereza Schönfeldová(1); Jakub Holovský(1, 2); Erkan Aydin (3); Zdeňka

Hájková(1); Lucie Landová(1,2); Neda Neyková(1); Antonín Fejfar(1) and Stefaan De Wolf(3)

1. Laboratory of Nanostructures and Nanomaterials, Institute of Physics, ASCR, Prague, Czech Republic.

2. Centre for Advanced Photovoltaics, Faculty of Electrical Engineering, Czech Technical University in Prague, Prague, Czech Republic.

3. KAUST Solar Center (KSC), King Abdullah University of Science and Technology (KAUST), Thuwal, Saudi Arabia.

Corresponding author: ledinsky@fzu.cz 


\section{ABSTRACT}

To gain insight in the properties of photovoltaic and light-emitting materials, detailed information about their optical absorption spectra is essential. Here, we elucidate the temperature dependence of such spectra for methylammonium lead iodide $\left(\mathrm{CH}_{3} \mathrm{NH}_{3} \mathrm{PbI}_{3}\right)$, with specific attention for its sub bandgap absorption edge (often referred to as Urbach energy). Based on these data, firstly, we find clear further evidence for the universality of the correlation between the Urbach energy and opencircuit voltage losses of solar cells. Secondly, we find that for $\mathrm{CH}_{3} \mathrm{NH}_{3} \mathrm{PbI}_{3}$ the static, temperatureindependent, contribution of the Urbach energy is $3.8 \pm 0.7 \mathrm{meV}$, which is smaller than that of crystalline silicon $(\mathrm{Si})$, gallium arsenide $(\mathrm{GaAs})$, indium phosphide (InP) or gallium nitride $(\mathrm{GaN})$, underlining the remarkable optoelectronic properties of perovskites.

\section{TOC GRAPHICS}

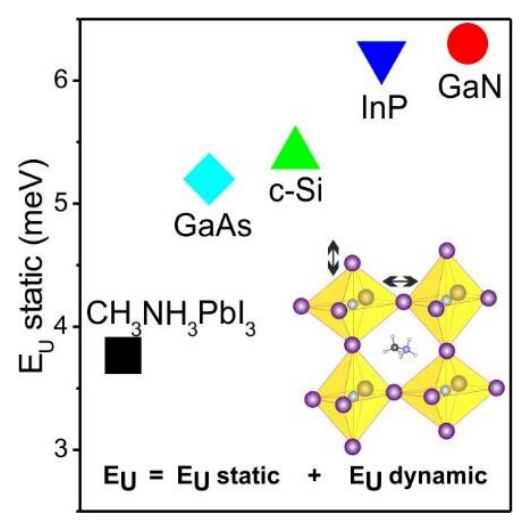


Perovskites have attracted in recent years tremendous attention for their potential for highperformance photovoltaics and optoelectronics at affordable cost. Since the fabrication of the first solar cells in 2009, ${ }^{1}$ this material class has become a topic of intense research, leading to reported solar cell power conversion efficiencies (PCE) now exceeding 23\%. ${ }^{2}$ This rapid surge in device performance can largely be attributed to the remarkable optoelectronic properties ${ }^{3-5}$ of the organometallic halide perovskite crystal (with typical structure $\mathrm{YPbX}_{3}, \mathrm{Y}=$ monovalent cations, $\mathrm{X}=$ halogen), used as photovoltaic absorber in perovskite solar cells. Earlier, to investigate these properties in detail, we used Fourier-transform photocurrent spectroscopy (FTPS) ${ }^{6}$ in combination with photothermal deflection spectroscopy (PDS) to measure the optical absorption properties of methylammonium lead iodide $\left(\mathrm{CH}_{3} \mathrm{NH}_{3} \mathrm{PbI}_{3}\right)$. Our studies revealed a sharp onset of its absorption coefficient, as well as a steep slope of its sub-bandgap absorption edge, expressed by $y^{7,8}$

$$
\alpha(E)=\alpha_{0} \exp \left(\frac{E-E_{C}}{E_{U}}\right),
$$

where $\alpha$ is the absorption coefficient, $\alpha_{0}$ and $E_{C}$ are material constants, and $E$ is the photon energy. The slope of this exponential decrease in absorption is often referred to as the 'Urbach energy $\left(E_{U}\right)^{\prime}$. Generally, small $E_{U}$ values are indicative of a high structural quality of the material ${ }^{9}$, which often also implies excellent electronic properties, such as a high carrier mobility ${ }^{10}$. On a device level, we found that $E_{U}$ also strongly dictates the minimal voltage deficiency ( $W_{O C}$, defined as the difference between bandgap voltage, $E_{G} / q$, and open-circuit voltage, $V_{O C}$ ), reachable with an optimized cell design; $q$ is the elementary charge. ${ }^{7}$ This relation seems to hold for most photovoltaic absorber layers, even though the link between $E_{U}$ and the minimal reported $W_{O C}$ value has remained so far mainly empirical. Nevertheless, it is clear that by considering the $E_{U}$ value a more realistic device efficiency limit may be obtained, compared with the Shockley-Queisser one $^{11}$. These empirical findings motivate the search for a deeper, more fundamental understanding 
of the relation between $E_{U}$ and $V_{O C}$. Notably, both of these parameters depend significantly on the temperature, ${ }^{12-14}$ which may offer an opportunity to gain further insight into their correlation. Here, we presents a detailed study of such temperature dependencies of $E_{U}$ and $V_{O C}$ for perovskites and compare obtained results with those of more established semiconductors used in optoelectronics.

Quite generally, beyond perovskites, $E_{U}$ can be seen as a metric for the energetic 'sharpness' of the band edge. Assuming the presence of a low density of localized active modes (which are associated with structural disorder), its temperature dependence can be expressed in terms of lattice vibrations. ${ }^{15}$ However, for highly disordered materials such as ternary compounds, additional parameters are required to describe the shift of the average phonon mode frequency. ${ }^{13,16} E_{U}$ 's temperature dependence is for $\mathrm{CH}_{3} \mathrm{NH}_{3} \mathrm{PbI}_{3}$ accurately described by two additive components: ${ }^{14,17}$

$$
E_{U}(T)=E_{U}(0)+\frac{2 E_{U}(0)}{\exp \left(\theta_{E} / T\right)-1}
$$

In this expression (2), $E_{U}(0)$ is temperature-independent, and referred to as the static component of $E_{U}$; its value scales with the intrinsic disorder of the material. The second term in (2) describes the phonon contribution to the measured value of the $E_{U}$, in other words, how the vibrations in the probed material influence its electrical properties; we refer to this term as the dynamic component of $E_{U}$. Here, $T$ is the absolute sample temperature, and $\Theta_{E}$ is the Einstein phonon temperature ${ }^{18}$ (i.e. the temperature with half-filled active phonon states). The Einstein phonon temperature is directly proportional to the energy of those phonons (vibration states) that interact substantially with free charges, thus limiting their mobility. ${ }^{16}$ The temperature dependence of $E_{U}$ has been characterized in detail for a number of semiconductors used in photovoltaics and optoelectronics, including GaAs, ${ }^{19} \mathrm{InP},{ }^{12} \mathrm{GaN}^{20}$, and hydrogenated amorphous silicon (a-Si:H). ${ }^{13}$ Only recently, a few studies have reported temperature-dependent absorptance measurements of perovskite films, and discussed changes in the absorption edge. ${ }^{21-24}$ However, higher-precision absorption 
measurements, beyond the range of three orders of magnitude are needed in order to provide an accurate evaluation of the $E_{U}$. This requirement cannot be met by direct calculation of the absorption spectra from transmission/reflection data. Therefore, in our study, we use indirect techniques based on photon interactions with the probed material, such as FTPS and contactless photoluminescence (PL) spectroscopy. In the case of FTPS, the photocurrent is used to determine the number of absorbed photons. Conversely, PL spectroscopy takes advantage from the reciprocity relation between photon emission and absorption, allowing us to use PL spectra to calculate the absorption coefficients down to $10^{-15} \mathrm{~cm}^{-1} \cdot 25$

Here, we specifically investigate the temperature dependence of $\mathrm{CH}_{3} \mathrm{NH}_{3} \mathrm{PbI}_{3}$ absorption spectra, either directly measured by FTPS or derived from PL spectra. From the temperature dependence of the $E_{U}$ for $\mathrm{CH}_{3} \mathrm{NH}_{3} \mathrm{PbI}_{3}$ we find that the cage phonon modes cause a broadening of the absorption edge, and that the density of electronically active static defects is extremely low, confirming the high optoelectronic tolerance of $\mathrm{CH}_{3} \mathrm{NH}_{3} \mathrm{PbI}_{3}$ for defects.

Fig. 1 shows the plots of the temperature-dependent FTPS absorption spectra of $\mathrm{CH}_{3} \mathrm{NH}_{3} \mathrm{PbI}_{3}$ films. The inset in Fig. 1, which shows an SEM top-view image of the $\mathrm{CH}_{3} \mathrm{NH}_{3} \mathrm{PbI}_{3}$ thin film used in our experiments, confirms the presence of a highly homogenous, smooth and compact film. The deposited films are $\sim 300 \mathrm{~nm}$ thick with grain sizes of $\sim 50-300 \mathrm{~nm}$. The following paragraphs discuss the key conclusions that can be drawn from the data presented in Fig. 1. 


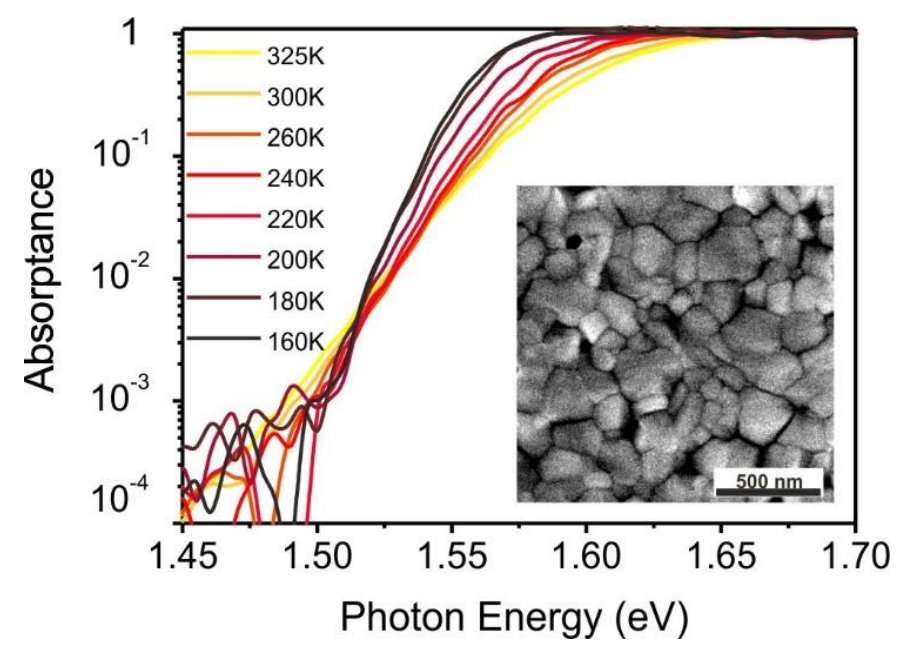

Fig. 1: Temperature dependence of the FTPS absorption spectra of $\mathrm{CH}_{3} \mathrm{NH}_{3} \mathrm{PbI}_{3}$ films. Temperature decreases, and the bandgap energy decreases, the absorption edge sharpens. All spectra intersect at one point, the so-called Urbach focus. The inset figure shows an SEM image of the $\mathrm{CH}_{3} \mathrm{NH}_{3} \mathrm{PbI}_{3}$ film prepared on a glass substrate

Firstly, the bandgap energy blue-shifts (i.e. widens) with increasing temperature. Generally, the electron-phonon coupling and thermal dilatation of the lattice are the two main underlying competing physical mechanisms that dictate the narrowing and broadening of the bandgap of a semiconductor with temperature, respectively. ${ }^{13,26}$ For most semiconductors, the latter effect is negligible, explaining why the bandgap energy usually decreases with temperature. ${ }^{12,13,23}$ The case of perovskites contrasts markedly with this: for these materials, the thermal dilatation of the lattice is extraordinarily high and, in fact, overrules the electron-phonon coupling effect, similarly to some chalcogenides. ${ }^{27}$ As a consequence, their bandgap actually broadens with increasing temperature. This blue-shift has important implications for photovoltaic device operation, under real outdoor conditions. ${ }^{28}$ With increasing temperature, $V_{O C}$ of solar cells usually decreases. ${ }^{29}$ However, for $\mathrm{CH}_{3} \mathrm{NH}_{3} \mathrm{PbI}_{3}$ solar cells, this trend is partially compensated by a broadening of the bandgap $\mathrm{p}^{24,30-33}$, in agreement with our results. 
Secondly, the absorption edge sharpens with decreasing temperature, i.e. $E_{U}$ decreases. An earlier reported temperature-dependent FTPS measurement ${ }^{24}$ did not reveal this trend; the $E_{U}$ appeared to be independent of temperature in this case. However, all other experimental data confirm the sharpening of the absorption edge with decreasing temperature. ${ }^{22,23,25,34}$ Therefore, this earlier measurement was most probably partially affected by other effects, associated with measurements artifacts under vacuum conditions. As described earlier, the temperature dependence of $E_{U}$ is given by the second, dynamic term in equation (2). Essentially, this term explains how an increasing phonon density leads to the broadening of the absorption edge, due to dynamic disorder (i.e. lattice vibrations) in the probed material. Notably, both the band gap blueshift and the broadening of the absorption edge are only dictated by the phonon density in the $\mathrm{CH}_{3} \mathrm{NH}_{3} \mathrm{PbI}_{3}$ film; the latter increases with temperature. Both effects (band gap blue-shift and edge broadening) shift the band edge with temperature but in opposite directions. As a consequence, all spectra intersect at one point, the so-called Urbach focus. Interestingly, the Urbach focus of $\mathrm{CH}_{3} \mathrm{NH}_{3} \mathrm{PbI}_{3}$ is located in a region that is experimentally accessible (contrasting with most other semiconductors). As shown in Fig. 1, we find (from FTPS) that it corresponds to a value of $1 \%$ of the absorptance, at a photon energy of $1.52 \mathrm{eV}$. The latter value is a general lower limit for the optical band gap of this material, and also the upper general limit for the $V_{\mathrm{OC}}{ }^{23}$

In order to measure the absorption spectra with even higher precision, we used PL microspectroscopy. The main advantages of this technique are its contactless nature and sensitivity over more than ten orders of magnitude, which make it especially suitable for detecting sub-band gap absorption, and thus for precisely evaluating $E_{U}$. As already stated, the evaluation of the absorptance spectrum $A_{B}(E)$ is based on the reciprocity between absorption and emission in both direct and indirect bandgap semiconductors ${ }^{25,35,36}$. The reciprocity theorem is expressed by ${ }^{25}$ 


$$
P L(E) \sim A_{B}(E) E^{2} \exp \left(-\frac{E}{k_{B} T}\right),
$$

where $\mathrm{PL}(\mathrm{E})$ is the photoluminescence spectrum, $E$ is the photon energy, $k_{\mathrm{B}}$ is the Boltzmann constant and $T$ is absolute temperature. From this expression, it is seen that the shape of the PL spectra is given by the number of photon absorption states $\left(E^{2}\right)$ and their occupancy (the exponential term in equation (3)). Reabsorption and reflection have to be accounted for when using this technique to measure absorption spectra of a semiconductor above its absorption edge. ${ }^{36}$ However, for the low absorption region, well below the bandgap, the absorption and absorptance spectral shapes are identical. The value of $E_{U}$ is calculated from this part of the spectra. Fig. 2 shows the measured PL spectra and corresponding calculated absorptance spectra of $\mathrm{CH}_{3} \mathrm{NH}_{3} \mathrm{PbI}_{3}$ as a function of temperature.
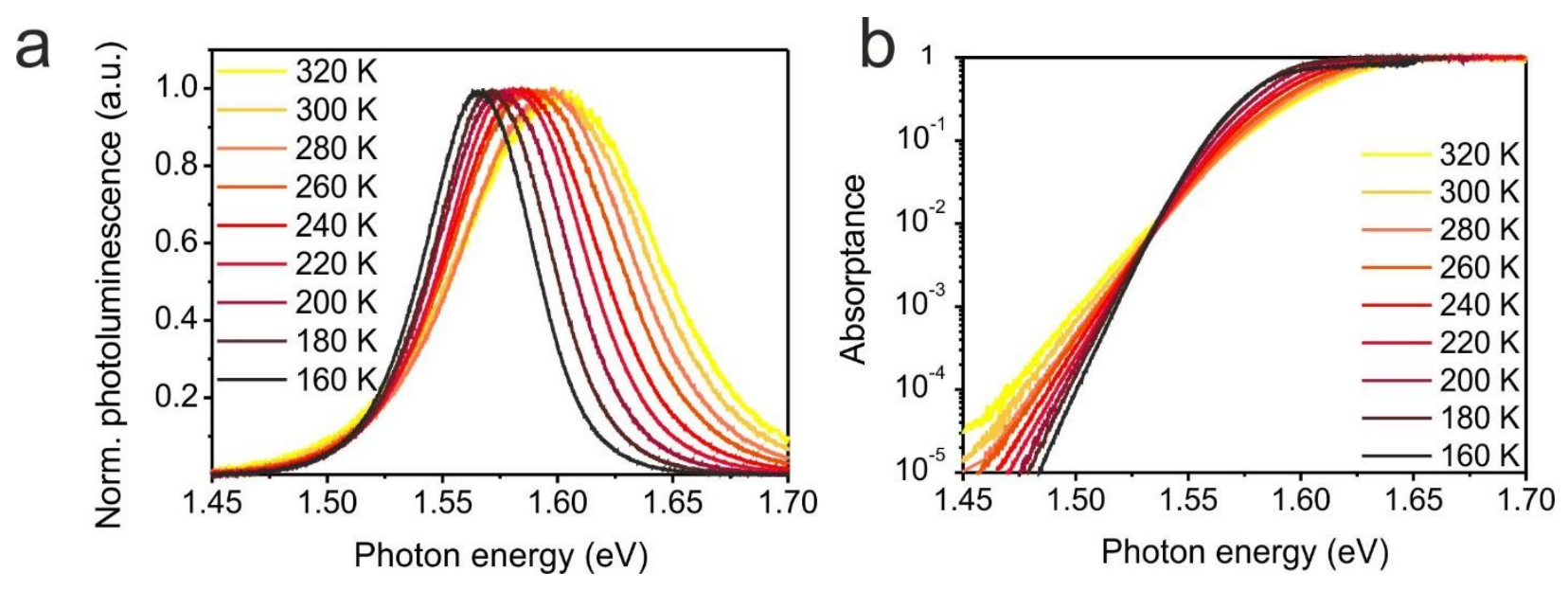

Fig. 2: Temperature dependence of the $\mathrm{CH}_{3} \mathrm{NH}_{3} \mathrm{PbI}_{3} \mathrm{PL}$ spectra (a) and PL based absorptance spectra (b). All absorptance spectra intersect at one point, the so-called Urbach focus. PL spectra, as well as the absorptance spectra, are normalized.

The PL shift to higher photon energies and the observed spectral broadening with increasing temperature is in agreement with the trends observed by Wright et al. ${ }^{34}$ and Barugkin et al. ${ }^{25}$ This 
is the combined effect of absorption-band broadening and the change in the energy distribution of the free carriers in the $\mathrm{CH}_{3} \mathrm{NH}_{3} \mathrm{PbI}_{3}$ film with increasing temperature. The temperature evolution of the absorptance spectra (Fig. 2.b) is very similar to that measured by FTPS (Fig. 1). A similar shift in bandgap energy and sharpening of the band edge is also observed. All absorption spectra intersect at the Urbach focus, which position is very similar to that obtained from FTPS measurements (absorptance of roughly $1 \%$ at a photon energy of $1.53 \mathrm{eV}$ ).

Fig. 3.a compares the temperature dependence of $E_{U}$, extracted from FTPS and PL measurements. The same plot also includes values derived from PL spectra reported by Barugkin et al..$^{25}$
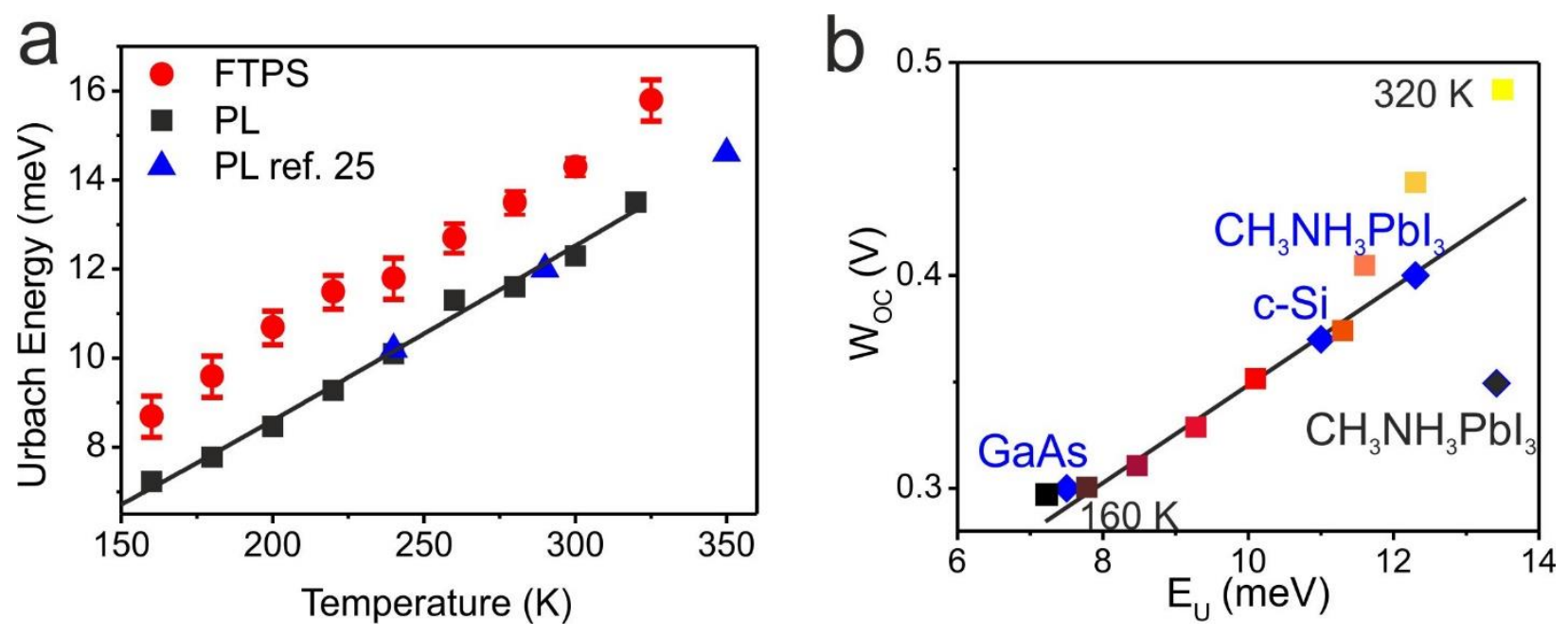

Fig. 3: (a) Temperature dependence of $E_{U}$ in $\mathrm{CH}_{3} \mathrm{NH}_{3} \mathrm{PbI}_{3}$ derived from FTPS (red dots) and PL (black squares) absorptance spectra. The black line is the $E_{U}$ dependence based on equation (2), the estimated error for $E_{U}$ calculated from PL spectra is $0.2 \mathrm{meV}$. Additionally, three blue triangles show $E_{U}$ values calculated from PL absorption measurements published in Ref. ${ }^{25}$ (b) Corresponding $\mathrm{W}_{\mathrm{OC}}$ and $\mathrm{E}_{\mathrm{U}}$ values, extracted from a $\mathrm{CH}_{3} \mathrm{NH}_{3} \mathrm{PbI}_{3}$ solar cell (squares). Each data pair is measured at the same temperature, the highest and lowest temperatures are marked in the 
graph, the temperature difference between neighboring points is $20 \mathrm{~K}$ (color code as in Fig.2). For comparison, room temperature data for $\mathrm{GaAs}^{37}{ }^{3} \mathrm{c}-\mathrm{Si}^{38}$ and $\mathrm{CH}_{3} \mathrm{NH}_{3} \mathrm{PbI}_{3}{ }^{39-45}$ minimal $\mathrm{W}_{\mathrm{OC}}$ cells have been added (diamonds).

First, the $\mathrm{E}_{\mathrm{U}}$ of $14.3 \mathrm{meV}$ measured at room temperature by FTPS is consistent with the values reported earlier for $\mathrm{CH}_{3} \mathrm{NH}_{3} \mathrm{PbI}_{3}\left(15 \mathrm{meV}^{7} 16 \mathrm{meV}^{24}\right.$ and $\left.14.8 \mathrm{meV}^{6}\right)$, and measured using the same technique and under the similar conditions. All data clearly show an increase in $E_{U}$ with temperature, consistent with the increase of the dynamic component in equation (2). We find that our PL-extracted $E_{U}$ data match very well with those calculated from the PL spectra obtained by Barugkin et al., ${ }^{25}$ despite using different $\mathrm{CH}_{3} \mathrm{NH}_{3} \mathrm{PbI}_{3}$ deposition processes (two-step deposition ${ }^{25}$ $v s$. one-step in our study), as well as PL excitation wavelengths. Next, we find that the $E_{U}$ obtained from FTPS data are consistently approximately $1.5 \mathrm{meV}$ higher than those obtained from PL. This discrepancy is even more striking when we compare the shapes of the FTPS and PL absorption spectra, at a given temperature (see Supplementary Information Fig. S1). Both spectra are shifted by $20 \mathrm{meV}$, but feature a very similar shape. This implies that this difference in $E_{U}$ is not fundamental, but must originate from the evaluation procedure. In the PL case, very low absorption values (below the Urbach focus) are used to extract the $E_{U}$. However, the FTPS absorption spectra below the Urbach focus are very noisy. Therefore, absorption values above the Urbach focus were used to extract the $E_{U}$. In this absorption range, the effect of band-to-band absorption starts to play a non-negligible role, which leads to higher extracted $E_{U}$ values. Notably, the same (higher) $\mathrm{E}_{\mathrm{U}}$ values are obtained from PL, when using the same part of the spectra as we used for the FTPS case. From this, we conclude that in general the values obtained from PL spectra measurements are more accurate, as they are unaffected by band-to-band absorption. 
The dependence of $\mathrm{E}_{\mathrm{U}}$ on temperature (extracted from PL) can be analyzed in greater detail by fitting the theoretical dependence (2) to the experimental data. From this, we can determine the constants describing the defect nature in the $\mathrm{CH}_{3} \mathrm{NH}_{3} \mathrm{PbI}_{3}$ films. First, the value of the $\Theta_{E}$ in (2) defines the energy of electronically active phonon modes, responsible for the electron-phonon scattering. In the case of $\mathrm{CH}_{3} \mathrm{NH}_{3} \mathrm{PbI}_{3}$, we find its value to be $(160 \pm 20) \mathrm{K}$, i.e. corresponding to a phonon energy of $(110 \pm 20) \mathrm{cm}^{-1}$. This value matches very well the Pb-I cage vibration modes situated at $50-120 \mathrm{~cm}^{-1}$ and the bound cage - organic cation phonon modes at $120-160 \mathrm{~cm}^{-1}$ obtained from Raman spectroscopy. ${ }^{46-49}$ This confirms an earlier PL study, based on the electronphonon coupling modeled by Froehlich coupling. ${ }^{34}$ The Raman shift of longitudinal optical phonons that play a dominant role in this interaction was calculated to be $(93 \pm 10) \mathrm{cm}^{-1}$. Therefore, we conclude that the electrical properties of $\mathrm{CH}_{3} \mathrm{NH}_{3} \mathrm{PbI}_{3}$ are mainly driven by cage vibrations. On the other hand, the organic cation vibration modes (vibrational as well as rotational, situated at $900 \mathrm{~cm}^{-1}$ and $2900 \mathrm{~cm}^{-1}$ ) do not substantially increase the electronically-active disorder in $\mathrm{CH}_{3} \mathrm{NH}_{3} \mathrm{PbI}_{3}$ films. Therefore, the movement of the organic cation does not lead to degradation of the $\mathrm{CH}_{3} \mathrm{NH}_{3} \mathrm{PbI}_{3}$ 's electronic quality.

From material characterization point of view, an even more important term in (2) is the number of electrically-active static defects, $E_{\mathrm{U}}(0)$. Localized defects, such as vacancies, interstitials etc., may act as deep recombination states in the bandgap of the probed material, which heuristically explains the relation between $E_{U}$ and $W_{\mathrm{OC}}$. Here, we find that this number is extraordinary low (3.8 $\pm 0.7 \mathrm{meV}$ ), underlining the high electronic tolerance to defects in $\mathrm{CH}_{3} \mathrm{NH}_{3} \mathrm{PbI}_{3}$, given by very low density of deep-defects (i.e. recombination-states) in ionic crystals in general. This is likely the key reason for the very high optoelectronic quality of perovskites. 
Furthermore, in Fig. 3.b we have plotted the dependence of the voltage deficiency, $W_{\mathrm{OC}}$, on $E_{U}$, for different temperatures. All data are for the same solar cell and its corresponding film, respectively. Following a trend similar to that reported in Ref. 4 for the most important photovoltaic materials, $W_{\mathrm{OC}}$ increases with $E_{\mathrm{U}}$ in a linear fashion, highlighting the impact of $E_{U}$ on the final properties of the optimized solar cell.

As benchmarks to our results, three more data points (blue), showing the best cell results at room temperature for $\mathrm{GaAs}^{37}{ }^{37} \mathrm{c}-\mathrm{Si}^{38}$ and $\mathrm{CH}_{3} \mathrm{NH}_{3} \mathrm{PbI}_{3}{ }^{39-45}$ (all cells with different compositions but almost identical voltage deficit of $0.4 \mathrm{~V}$ ) are added to the graph. The right-most black point added to the graph belongs to the $\mathrm{V}_{\mathrm{OC}}$ record perovskite cell, ${ }^{50}$ featuring an extraordinary low voltage deficit of $0.34 \mathrm{~V}$. Based on the published absorption curve we calculated its $E_{U}$ to be $13.5 \mathrm{meV}$. This cell does not fit the linear trend of the other semiconductor. This may be caused by the PL measurement on the finalized cell (not on the stand alone film), where the perovskite material could be affected by its selective contacts, or voltage bias preconditioning before the currentvoltage measurement; more work may be needed to clarify this discrepancy.

We can clearly see that our $\mathrm{CH}_{3} \mathrm{NH}_{3} \mathrm{PbI}_{3}$ cell has a slightly higher $\mathrm{W}_{\mathrm{OC}}$ (at room temperature) compared with the group of high quality $\mathrm{CH}_{3} \mathrm{NH}_{3} \mathrm{PbI}_{3}$ cells. This is not due to the properties of our $\mathrm{CH}_{3} \mathrm{NH}_{3} \mathrm{PbI}_{3}$ film, but rather because of the slight band misalignment at the electron and hole contacts in our specific device architecture. For lower temperatures, the $E_{U}$ of $\mathrm{CH}_{3} \mathrm{NH}_{3} \mathrm{PbI}_{3}$ decreases to the level that $\mathrm{c}-\mathrm{Si}$ and GaAs reaches at room temperature. The same $W_{\mathrm{OC}}$ was obtained for these record solar cells as well as for our $\mathrm{CH}_{3} \mathrm{NH}_{3} \mathrm{PbI}_{3}$ solar cells. This means that the band alignment in the probed cell at lower temperature is almost ideal. Based on these results, we can conclude that the $W_{\mathrm{OC}}$ of an optimized cell (from $V_{O C}$ point of view) is generally directly dictated 
by the $E_{U}$ of its photovoltaic absorber, independently of the temperature or other specific cell parameters.

Finally, we compare the temperature dependence of $E_{U}$ of polycrystalline solution-prepared $\mathrm{CH}_{3} \mathrm{NH}_{3} \mathrm{PbI}_{3}$ (as already show in Fig. 3a) shown in Fig. 4 with those of a number of typical semiconductors used in solar cells and optoelectronics, namely single crystals of $\mathrm{GaN}^{20}{ }^{20} \mathrm{InP},{ }^{12}$ $\mathrm{GaAs}^{19}$ and $\mathrm{Si}$ (calculation based on data from ${ }^{36}$ ).

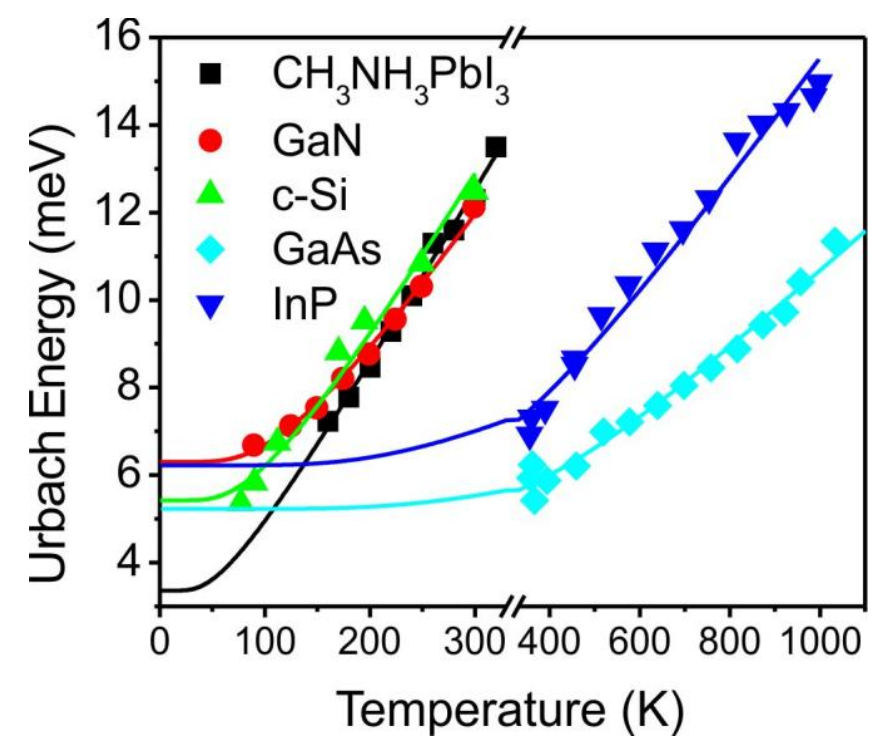

Fig. 4: Comparison of the $E_{U}$ temperature dependences for selected standard bulk crystalline semiconductors and $\mathrm{CH}_{3} \mathrm{NH}_{3} \mathrm{PbI}_{3}$ thin films. The temperature scale is split into two parts with a different range. Lines are fits of equation (2) to the data.

It is important to underline that all semiconductors from Fig. 4 (except $\mathrm{CH}_{3} \mathrm{NH}_{3} \mathrm{PbI}_{3}$ ) are highly ordered crystalline materials, prepared under demanding purification and crystallization conditions, often involving high temperatures well above $1000 \mathrm{~K} \cdot .^{19,20,36}$ Therefore, the higher value of the static part of the $E_{U}\left(E_{\mathrm{U}}(0)\right)$ for the latter materials (between 5.2 and $6.3 \mathrm{meV}$ ), compared to the value for $\mathrm{CH}_{3} \mathrm{NH}_{3} \mathrm{PbI}_{3}$ is surprising. Most standard thin-film semiconductors such 
as a-Si:H, ${ }^{13} \mathrm{ZnO},{ }^{51}$ and $\mathrm{CuIn}_{3} \mathrm{Te}_{8}{ }^{18}$ have $E_{\mathrm{U}}(0)$ values that are higher by one order of magnitude. Another interesting observation is the very similar slopes of $E_{U} v s$. temperature for $\mathrm{CH}_{3} \mathrm{NH}_{3} \mathrm{PbI}_{3}$, c-Si and GaN. This is given by the lower phonon energy in these materials, leading to electronphonon scattering and, consequently, to higher $E_{U}$ values at room temperature. All extracted values are presented in supporting information Table S1.

To conclude, we have measured temperature dependence of $\mathrm{CH}_{3} \mathrm{NH}_{3} \mathrm{PbI}_{3} E_{U}$ by two independent methods, PL spectroscopy and FTPS. We find that PL spectroscopy allows for the extraction of more accurate $E_{U}$ values, compared to FTPS or PDS. Based on the $E_{U}$ temperature dependence fit, we show that $\mathrm{CH}_{3} \mathrm{NH}_{3} \mathrm{PbI}_{3}$ has an extremely low number of active static defects, even lower than crystalline silicon or GaAs. The value of the phonon frequency describing the dynamic defect component (electron-phonon scattering based) of the $E_{U}$ is $(110 \pm 20) \mathrm{cm}^{-1}$. This means that the main contribution to the dynamic defects comes from the cage vibration part of the phonon spectrum and that the movement of the large cation in the perovskite cage plays only a minor role in the $\mathrm{CH}_{3} \mathrm{NH}_{3} \mathrm{PbI}_{3}$ electronic properties. Finally, we have shown that the minimal obtainable $W_{O C}$ of an optimized solar cell are largely dictated by the $E_{U}$. Our work underlines how PL microspectroscopy offers a contactless and fast measurement, to reveal the potential usage of new materials in solar cell applications.

\section{Experimental Methods}

The temperature dependence of the absorption spectra is obtained using FTPS. ${ }^{3}$ This method detects a photoconductivity response upon illumination modulated by a Thermo Nicolet 8700 FTIR spectrophotometer, at scan speed of $0.16 \mathrm{~cm} / \mathrm{s}$. The probe beam illuminating the sample is the white light from a halogen lamp (intensity of approximately $50 \mathrm{~mW} / \mathrm{cm}^{2}$, i.e. $0.5 \mathrm{sun}$ ). PL 
spectra are measured using a $\mathrm{HeCd} 442 \mathrm{~nm}$ excitation laser in a Renishaw REFLEX microspectroscope. The intensity of the laser light is reduced to the equivalent of about 4 suns, in order to prevent any structural degradation occurring during measurements. ${ }^{36}$

\section{ACKNOWLEDGMENT}

Authors thank to David Cahen for fruitful discussions. We acknowledge the support of Czech Science Foundation Project No. 17-26041Y, Operational Programme Research, Development and Education financed by the European Structural and Investment Funds and the Czech Ministry of Education, Youth and Sports (Project No. CZ.02.1.01/0.0/0.0/16_019/0000760 - SOLID21 and No. CZ.02.1.01/0.0/0.0/15_003/0000464 - Centre of Advanced Photovoltaics). Erkan Aydin and Stefaan De Wolf acknowledge to King Abdullah University of Science and Technology (KAUST) for the financial support under award no. OSR-CARF URF/1/3079-33-01.

Supporting Information Available

Supporting Information contains description of samples/solar cells preparation, experimental methods section, detail comparison of measured FTPS and PL spectra, temperature dependence of the PL intensity and basic photovoltaic properties of used solar cell.

References 
(1) Kojima, A.; Teshima, K.; Shirai, Y.; Miyasaka, T. Organometal Halide Perovskites as Visible-Light Sensitizers for Photovoltaic Cells. J. Am. Chem. Soc. 2009, 131 (17), 6050-+. https://doi.org/10.1021/ja809598r.

(2) Jeon, N. J.; Na, H.; Jung, E. H.; Yang, T.-Y.; Lee, Y. G.; Kim, G.; Shin, H.-W.; Seok, S. I.; Lee, J.; Seo, J. A Fluorene-Terminated Hole-Transporting Material for Highly Efficient and Stable Perovskite Solar Cells. Nat. Energy 2018, 1. https://doi.org/10.1038/s41560-018-0200-6.

(3) deQuilettes, D. W.; Koch, S.; Burke, S.; Paranji, R. K.; Shropshire, A. J.; Ziffer, M. E.; Ginger, D. S. Photoluminescence Lifetimes Exceeding $8 \mathrm{Ms}$ and Quantum Yields Exceeding 30\% in Hybrid Perovskite Thin Films by Ligand Passivation. ACS Energy Lett. 2016, 1 (2), 438-444. https://doi.org/10.1021/acsenergylett.6b00236.

(4) Stranks, S. D.; Eperon, G. E.; Grancini, G.; Menelaou, C.; Alcocer, M. J. P.; Leijtens, T.; Herz, L. M.; Petrozza, A.; Snaith, H. J. Electron-Hole Diffusion Lengths Exceeding 1 Micrometer in an Organometal Trihalide Perovskite Absorber. Science 2013, 342 (6156), 341-344. https://doi.org/10.1126/science.1243982.

(5) Shi, D.; Adinolfi, V.; Comin, R.; Yuan, M.; Alarousu, E.; Buin, A.; Chen, Y.; Hoogland, S.; Rothenberger, A.; Katsiev, K.; et al. Low Trap-State Density and Long Carrier Diffusion in Organolead Trihalide Perovskite Single Crystals. Science 2015, 347 (6221), 519-522. https://doi.org/10.1126/science.aaa2725.

(6) Holovský, J.; De Wolf, S.; Werner, J.; Remeš, Z.; Müller, M.; Neykova, N.; Ledinský, M.; Černá, L.; Hrzina, P.; Löper, P.; et al. Photocurrent Spectroscopy of Perovskite Layers and Solar Cells: A Sensitive Probe of Material Degradation. J. Phys. Chem. Lett. 2017, 8 (4), 838-843. https://doi.org/10.1021/acs.jpclett.6b02854.

(7) De Wolf, S.; Holovsky, J.; Moon, S.-J.; Loeper, P.; Niesen, B.; Ledinsky, M.; Haug, F.-J.; Yum, J.-H.; Ballif, C. Organometallic Halide Perovskites: Sharp Optical Absorption Edge and Its Relation to Photovoltaic Performance. J. Phys. Chem. Lett. 2014, 5 (6), 1035-1039. https://doi.org/10.1021/jz500279b.

(8) Urbach, F. The Long-Wavelength Edge of Photographic Sensitivity and of the Electronic Absorption of Solids. Phys. Rev. 1953, 92 (5), 1324-1324. https://doi.org/10.1103/PhysRev.92.1324.

(9) Stutzmann, M. The Defect Density in Amorphous Silicon. Philos. Mag. B 1989, 60 (4), 531-546. https://doi.org/10.1080/13642818908205926.

(10) Wehrspohn, R. B.; Deane, S. C.; French, I. D.; Gale, I.; Hewett, J.; Powell, M. J.; Robertson, J. Relative Importance of the Si-Si Bond and $\mathrm{Si}-\mathrm{H}$ Bond for the Stability of Amorphous Silicon Thin Film Transistors. J. Appl. Phys. 1999, 87 (1), 144-154. https://doi.org/10.1063/1.371836.

(11) Jean, J.; Mahony, T. S.; Bozyigit, D.; Sponseller, M.; Holovský, J.; Bawendi, M. G.; Bulović, V. Radiative Efficiency Limit with Band Tailing Exceeds 30\% for Quantum Dot Solar Cells. ACS Energy Lett. 2017, 2 (11), 2616-2624. https://doi.org/10.1021/acsenergylett.7b00923.

(12) Beaudoin, M.; DeVries, A. J. G.; Johnson, S. R.; Laman, H.; Tiedje, T. Optical Absorption Edge of Semi-Insulating GaAs and InP at High Temperatures. Appl. Phys. Lett. 1997, 70 (26), 3540-3542. https://doi.org/10.1063/1.119226.

(13) Cody, G. D.; Tiedje, T.; Abeles, B.; Brooks, B.; Goldstein, Y. Disorder and the Optical-Absorption Edge of Hydrogenated Amorphous Silicon. Phys. Rev. Lett. 1981, 47 (20), 1480-1483. https://doi.org/10.1103/PhysRevLett.47.1480.

(14) Studenyak, I.; Kranjec, M.; Kurik, M. Urbach Rule in Solid State Physics. Int. J. Opt. Appl. 2014, 4 (3), 76-83.

(15) Sumi, H.; Toyozawa, Y. Urbach-Martienseen Rule and Exciton Trapped Momentarily by Lattice Vibrations. J. Phys. Soc. Jpn. 1971, 31 (2), 342-358. https://doi.org/10.1143/JPSJ.31.342. 
(16) Wasim, S. M.; Rincón, C.; Marín, G.; Bocaranda, P.; Hernández, E.; Bonalde, I.; Medina, E. Effect of Structural Disorder on the Urbach Energy in Cu Ternaries. Phys. Rev. B 2001, 64 (19), 195101. https://doi.org/10.1103/PhysRevB.64.195101.

(17) Kurik, M. V. Urbach Rule. Phys. Status Solidi A 1971, 8 (1), 9-45. https://doi.org/10.1002/pssa.2210080102.

(18) Bonalde, I.; Medina, E.; Wasim, S. M. Temperature Dependence of the Urbach Energy in Ordered Defect Compounds Cu-III3-VI5 and Cu-III5-VI8. J. Phys. Chem. Solids 2005, 66 (11), 1865-1867. https://doi.org/10.1016/j.jpcs.2005.10.002.

(19) Johnson, S. R.; Tiedje, T. Temperature Dependence of the Urbach Edge in GaAs. J. Appl. Phys. 1995, 78 (9), 5609-5613. https://doi.org/10.1063/1.359683.

(20) Chichibu, S.; Mizutani, T.; Shioda, T.; Nakanishi, H.; Deguchi, T.; Azuhata, T.; Sota, T.; Nakamura, S. Urbach-Martienssen Tails in a Wurtzite GaN Epilayer. Appl. Phys. Lett. 1997, 70 (25), 3440-3442. https://doi.org/10.1063/1.119196.

(21) Soufiani, A. M.; Huang, F.; Reece, P.; Sheng, R.; Ho-Baillie, A.; Green, M. A. Polaronic Exciton Binding Energy in lodide and Bromide Organic-Inorganic Lead Halide Perovskites. Appl. Phys. Lett. 2015, 107 (23), 231902. https://doi.org/10.1063/1.4936418.

(22) Green, M. A.; Jiang, Y.; Soufiani, A. M.; Ho-Baillie, A. Optical Properties of Photovoltaic OrganicInorganic Lead Halide Perovskites. J. Phys. Chem. Lett. 2015, 6 (23), 4774-4785. https://doi.org/10.1021/acs.jpclett.5b01865.

(23) Singh, S.; Li, C.; Panzer, F.; Narasimhan, K. L.; Graeser, A.; Gujar, T. P.; Köhler, A.; Thelakkat, M.; Huettner, S.; Kabra, D. Effect of Thermal and Structural Disorder on the Electronic Structure of Hybrid Perovskite Semiconductor CH3NH3PbI3. J. Phys. Chem. Lett. 2016, 7 (15), 3014-3021. https://doi.org/10.1021/acs.jpclett.6b01207.

(24) Patel, J. B.; Lin, Q.; Zadvorna, O.; Davies, C. L.; Herz, L. M.; Johnston, M. B. Photocurrent Spectroscopy of Perovskite Solar Cells Over a Wide Temperature Range from 15 to 350 K. J. Phys. Chem. Lett. 2018, 9 (1), 263-268. https://doi.org/10.1021/acs.jpclett.7b02935.

(25) Barugkin, C.; Cong, J.; Duong, T.; Rahman, S.; Nguyen, H. T.; Macdonald, D.; White, T. P.; Catchpole, K. R. Ultralow Absorption Coefficient and Temperature Dependence of Radiative Recombination of CH3NH3Pbl3 Perovskite from Photoluminescence. J. Phys. Chem. Lett. 2015, 6 (5), 767-772. https://doi.org/10.1021/acs.jpclett.5b00044.

(26) Varshni, Y. P. Temperature Dependence of the Energy Gap in Semiconductors. Physica 1967, 34 (1), 149-154. https://doi.org/10.1016/0031-8914(67)90062-6.

(27) Martinez, G.; Schlüter, M.; Cohen, M. L. Electronic Structure of PbSe and PbTe II. Optical Properties. Phys. Rev. B 1975, 11 (2), 660-670. https://doi.org/10.1103/PhysRevB.11.660.

(28) Dupré, O.; Niesen, B.; De Wolf, S.; Ballif, C. Field Performance versus Standard Test Condition Efficiency of Tandem Solar Cells and the Singular Case of Perovskites/Silicon Devices. J. Phys. Chem. Lett. 2018, 9 (2), 446-458. https://doi.org/10.1021/acs.jpclett.7b02277.

(29) Löper, P.; Pysch, D.; Richter, A.; Hermle, M.; Janz, S.; Zacharias, M.; Glunz, S. W. Analysis of the Temperature Dependence of the Open-Circuit Voltage. Energy Procedia 2012, 27, 135-142. https://doi.org/10.1016/j.egypro.2012.07.041.

(30) Zhang, H.; Qiao, X.; Shen, Y.; Moehl, T.; Zakeeruddin, S. M.; Grätzel, M.; Wang, M. Photovoltaic Behaviour of Lead Methylammonium Triiodide Perovskite Solar Cells down to 80 K. J. Mater. Chem. A 2015, 3 (22), 11762-11767. https://doi.org/10.1039/C5TA02206A.

(31) Leong, W. L.; Ooi, Z.-E.; Sabba, D.; Yi, C.; Zakeeruddin, S. M.; Graetzel, M.; Gordon, J. M.; Katz, E. A.; Mathews, N. Identifying Fundamental Limitations in Halide Perovskite Solar Cells. Adv. Mater. 2016, 28 (12), 2439-2445. https://doi.org/10.1002/adma.201505480.

(32) Jacobsson, T. J.; Tress, W.; Correa-Baena, J.-P.; Edvinsson, T.; Hagfeldt, A. Room Temperature as a Goldilocks Environment for $\mathrm{CH} 3 \mathrm{NH} 3 \mathrm{Pbl} 3$ Perovskite Solar Cells: The Importance of Temperature 
on Device Performance. J. Phys. Chem. C 2016, 120 (21), 11382-11393.

https://doi.org/10.1021/acs.jpcc.6b02858.

(33) Phuong, L. Q.; Nakaike, Y.; Wakamiya, A.; Kanemitsu, Y. Free Excitons and Exciton-Phonon Coupling in $\mathrm{CH} 3 \mathrm{NH} 3 \mathrm{PbI} 3$ Single Crystals Revealed by Photocurrent and Photoluminescence Measurements at Low Temperatures. J. Phys. Chem. Lett. 2016, 7 (23), 4905-4910. https://doi.org/10.1021/acs.jpclett.6b02432.

(34) Wright, A. D.; Verdi, C.; Milot, R. L.; Eperon, G. E.; Pérez-Osorio, M. A.; Snaith, H. J.; Giustino, F.; Johnston, M. B.; Herz, L. M. Electron-Phonon Coupling in Hybrid Lead Halide Perovskites. Nat. Commun. 2016, 7, 11755. https://doi.org/10.1038/ncomms11755.

(35) Shockley, W.; Queisser, H. J. Detailed Balance Limit of Efficiency of P-n Junction Solar Cells. J. Appl. Phys. 1961, 32 (3), 510-519. https://doi.org/10.1063/1.1736034.

(36) Trupke, T.; Green, M. A.; Würfel, P.; Altermatt, P. P.; Wang, A.; Zhao, J.; Corkish, R. Temperature Dependence of the Radiative Recombination Coefficient of Intrinsic Crystalline Silicon. J. Appl. Phys. 2003, 94 (8), 4930-4937. https://doi.org/10.1063/1.1610231.

(37) Miller, O. D.; Yablonovitch, E.; Kurtz, S. R. Strong Internal and External Luminescence as Solar Cells Approach the Shockley-Queisser Limit. IEEE J. Photovolt. 2012, 2 (3), 303-311. https://doi.org/10.1109/JPHOTOV.2012.2198434.

(38) Taguchi, M.; Yano, A.; Tohoda, S.; Matsuyama, K.; Nakamura, Y.; Nishiwaki, T.; Fujita, K.; Maruyama, E. 24.7\% Record Efficiency HIT Solar Cell on Thin Silicon Wafer. IEEE J. Photovolt. 2014, 4 (1), 96-99. https://doi.org/10.1109/JPHOTOV.2013.2282737.

(39) Pérez-del-Rey, D.; Boix, P. P.; Sessolo, M.; Hadipour, A.; Bolink, H. J. Interfacial Modification for High-Efficiency Vapor-Phase-Deposited Perovskite Solar Cells Based on a Metal Oxide Buffer Layer. J. Phys. Chem. Lett. 2018, 9 (5), 1041-1046. https://doi.org/10.1021/acs.jpclett.7b03361.

(40) Wolff, C. M.; Zu, F.; Paulke, A.; Toro, L. P.; Koch, N.; Neher, D. Reduced Interface-Mediated Recombination for High Open-Circuit Voltages in CH3NH3PbI3 Solar Cells. Adv. Mater. 2017, 29 (28), 1700159. https://doi.org/10.1002/adma.201700159.

(41) Saliba, M.; Matsui, T.; Domanski, K.; Seo, J.-Y.; Ummadisingu, A.; Zakeeruddin, S. M.; CorreaBaena, J.-P.; Tress, W. R.; Abate, A.; Hagfeldt, A.; et al. Incorporation of Rubidium Cations into Perovskite Solar Cells Improves Photovoltaic Performance. Science 2016, 354 (6309), 206-209. https://doi.org/10.1126/science.aah5557.

(42) Anaraki, E. H.; Kermanpur, A.; Steier, L.; Domanski, K.; Matsui, T.; Tress, W.; Saliba, M.; Abate, A.; Grätzel, M.; Hagfeldt, A.; et al. Highly Efficient and Stable Planar Perovskite Solar Cells by Solution-Processed Tin Oxide. Energy Environ. Sci. 2016, 9 (10), 3128-3134. https://doi.org/10.1039/C6EE02390H.

(43) Luo, D.; Yang, W.; Wang, Z.; Sadhanala, A.; Hu, Q.; Su, R.; Shivanna, R.; Trindade, G. F.; Watts, J. F.; Xu, Z.; et al. Enhanced Photovoltage for Inverted Planar Heterojunction Perovskite Solar Cells. Science 2018, 360 (6396), 1442-1446. https://doi.org/10.1126/science.aap9282.

(44) Lee, M. M.; Teuscher, J.; Miyasaka, T.; Murakami, T. N.; Snaith, H. J. Efficient Hybrid Solar Cells Based on Meso-Superstructured Organometal Halide Perovskites. Science 2012, 338 (6107), 643647. https://doi.org/10.1126/science.1228604.

(45) Tan, H.; Jain, A.; Voznyy, O.; Lan, X.; Arquer, F. P. G. de; Fan, J. Z.; Quintero-Bermudez, R.; Yuan, M.; Zhang, B.; Zhao, Y.; et al. Efficient and Stable Solution-Processed Planar Perovskite Solar Cells via Contact Passivation. Science 2017, 355 (6326), 722-726. https://doi.org/10.1126/science.aai9081.

(46) Ledinský, M.; Löper, P.; Niesen, B.; Holovský, J.; Moon, S.-J.; Yum, J.-H.; De Wolf, S.; Fejfar, A.; Ballif, C. Raman Spectroscopy of Organic-Inorganic Halide Perovskites. J. Phys. Chem. Lett. 2015, 6 (3), 401-406. https://doi.org/10.1021/jz5026323. 
(47) Brivio, F.; Frost, J. M.; Skelton, J. M.; Jackson, A. J.; Weber, O. J.; Weller, M. T.; Goñi, A. R.; Leguy, A. M. A.; Barnes, P. R. F.; Walsh, A. Lattice Dynamics and Vibrational Spectra of the Orthorhombic, Tetragonal, and Cubic Phases of Methylammonium Lead lodide. Phys. Rev. B 2015, 92 (14), 144308. https://doi.org/10.1103/PhysRevB.92.144308.

(48) Quarti, C.; Grancini, G.; Mosconi, E.; Bruno, P.; Ball, J. M.; Lee, M. M.; Snaith, H. J.; Petrozza, A.; De Angelis, F. The Raman Spectrum of the $\mathrm{CH}(3) \mathrm{NH}(3) \mathrm{Pbl}(3)$ Hybrid Perovskite: Interplay of Theory and Experiment. J. Phys. Chem. Lett. 2014, 5 (2), 279-284. https://doi.org/10.1021/jz402589q.

(49) Grancini, G.; Marras, S.; Prato, M.; Giannini, C.; Quarti, C.; De Angelis, F.; De Bastiani, M.; Eperon, G. E.; Snaith, H. J.; Manna, L.; et al. The Impact of the Crystallization Processes on the Structural and Optical Properties of Hybrid Perovskite Films for Photovoltaics. J. Phys. Chem. Lett. 2014, 5 (21), 3836-3842. https://doi.org/10.1021/jz501877h.

(50) Liu, Z.; Krückemeier, L.; Krogmeier, B.; Klingebiel, B.; Márquez, J. A.; Levcenko, S.; Öz, S.; Mathur, S.; Rau, U.; Unold, T.; et al. Open-Circuit Voltages Exceeding 1.26 V in Planar Methylammonium Lead lodide Perovskite Solar Cells. ACS Energy Lett. 2019, 4 (1), 110-117. https://doi.org/10.1021/acsenergylett.8b01906.

(51) Rai, R. C. Analysis of the Urbach Tails in Absorption Spectra of Undoped ZnO Thin Films. J. Appl. Phys. 2013, 113 (15), 153508. https://doi.org/10.1063/1.4801900. 